\title{
READING ONLINE: EVALUATION OF ONLINE SOURCES CREDIBILITY
}

\author{
Fatimah Tuzahra \\ Universitas Sriwijaya
}

fatiimahtzhr@outlook.com

\begin{abstract}
The vast amount of online information demands readers to check its credibility since fabricated information has widely been misused and also supported by a lack of filters in web-based sources in ensuring its quality. In practice, checking the credibility of an online source is not an easy task to do as searchers need to consider several aspects in its application. This happens due to some factors, such as language and searchers' willingness in identifying the quality of online information. This paper focuses on the evaluation of online sources' credibility covering scholars' definitions of online sources credibility, English-native and foreign searchers' perspective in judging online sources, and varied criteria applied in online sources credibility in which give insight for readers about this issue and provide references for further study.
\end{abstract}

Keywords: Online sources, Evaluation, Credibility

To cite this article:

Tuzahra, F. (2021). Reading Online: Evaluation of Online Sources Credibility. Journal of Research on Language Education, 2(1), 32-36.

\section{INTRODUCTION}

The dynamic changes in society as a result of the advancement of technology influence the way on how people search for information as Oktaviani \& Desiarti (2017) said that technology has influenced many aspect of human life in the $21^{\text {st }}$ century. In the past few decades, people relied on traditional media to get the sources that they need. Meanwhile, there is a significant transformation as rapidly developed technology plays an important role in providing a convenient platform to access information through electronic media. It is in line with Sari (2020) who mentioned that advanced technology helps people to maximize the use of the internet and digital media to gain abundant sources or information. Therefore, people nowadays tend to use more electronic media integrated with the internet in getting sources, especially digital native (Oktaviani \& Mandasari, 2020). The reliance on searching for information on the internet, on the other hand, leads people to the problematic situation in identifying misleading information since the availability of varied sources on the web has led to confusion in determining what and whom to trust (Robins et. al, 2010; Fisher et al. 2008; Goldbeck, 2008). Besides, Tudjman and Mikelic (2003) emphasized that some misinformation misguidedly has been used for information on the internet since it is found that the internet has a limited number of filters toward accessible information online (Flanagin \& Metzger, 2000; Johnson \& Kaye, 1998; Rieh \& Belkin, 1998).

Comparing to conventional based information, people should verify sources anytime they access onlinebased information. This should be done since the massive quantity and availability of online information creates issues about credibility as the source of information since its quality and accuracy are less clear than traditionalbased information. Besides, the information found online is more prone to a modification that needs efforts to detect (Alexander \& Tate, 1999; Flanagin \& Metzger, 2000). Hence, the process of validating information is emphasized due to the lack of professional gatekeepers in ensuring the accuracy of sources because of the abundance of information that would need to be scrutinized. Johnson and Kaye (1998) stated that the insufficient number of reviews in web-based information leads to hesitancy in confirming the quality of sources. As the result, evaluating online sources is indeed important. However, the increasing dependence on searching sources online does not necessarily make people especially students to judge its quality. This is proven from the study of Media Awareness Network (2001) that the youngest people do not check the quality of online information for its credibility, reliability, or authenticity. In a similar vein, the report of the Stanford University History and Civic group which examined 7,804 of both middle and college students across 12 states about their ability in judging the credibility of information outlined that students were suffering to differentiate reliable sources over the internet. Furthermore, they were also confused to distinguish between advertisements and news articles from websites. 
Another study by Lubans (1999) illustrated while most students involved in this study indicated that online sources assist them in obtaining as much information that needs, on the contrary, the students also think that the quality of information is not important for them. Thus, based on studies, it can be concluded that there is hesitancy among students in checking sources that they found online.

Scholars whose expertise in credibility like Wathen \& Burkell (2002, p. 153) define credibility as something that is associated with believability. While Rieh (2010, p. 1338) refers to credibility as people's assessment of whether the information is trustworthy based on their expertise and knowledge. Information credibility, additionally, refers to the ability of someone in recognizing information that he or she believes to be true. When checking credibility, the ability of online reading is also considered as it covers searching for and evaluating the information aspects. Serafni (2012) stated that reading online demands readers to interpret and negotiate both the design element and graphic images to comprehend the written language. Lacking reading online ability may lead readers to get confused in evaluating the credibility of sources, and this could be one of the factors that caused unwillingness to check the credibility of online sources. This paper accordingly initiates to highlight about the evaluation of online sources credibility, covering searchers' perception toward online sources credibility evaluation and varied criteria applied in evaluating.

\section{Online Sources Credibility}

The term credibility cannot be separated from the evaluation of online source credibility. As an example, Judd et al. (2006) applied credibility and relevance of teaching undergraduate students in assessing information from websites. Fogg (2003, p.122) defines credibility as authenticity. Rieh (2010, p. 1338) illustrates information credibility as people's judgment to determine whether information that they get is credible according to their expertise and knowledge. There are two notions of credibility such as trustworthiness and expertise (Rieh, 2014). Accordingly, trustworthy information is usually defined as real, equal, accurate, and unbiased (Rieh, 2014) while Fogg (2003, p.124) illustrates expertise as apparent knowledge, skill as well as experience of sources.

Traditionally, credibility is distinguished into three aspects, source credibility, message, and media credibility. O' Kaffee (1990, p. 130-131) defines source credibility as an assessment done by a searcher regarding the credibility of a communicator. Message credibility emphasis how the message aspects such as content, structure and language, and presentation can influence opinions toward the credibility of information (Rieh, 2010) and media credibility emphasizes the believability of varied media networks throughout a message is sent (Roper, 1985). Flanagin \& Metzger (2008) propose three kinds of credibility: conferred credibility, tabulated credibility, and emergent credibility. Conferred credibility refers to a condition where people identify credibility based on other sources' good reputations, not from the real source. Tabulated credibility depicts people's judgment about credibility based on peer review of individual, group, or product, and emergent credibility comes from enriched sources on the internet like social networking sites made by individuals (Rieh, 2008).

According to Harris (1997), the credibility assessment involves assessment of authority, consistency, style, and accuracy of the text, assessment of the goal of the text, and authentication of the information in the text. Metzger and Flanagin (2013) suggested six methods in evaluating information credibility that is, reputation, authorization, steadiness, self-conformation, probability violation, and convincing intent. The reputation heuristic known as acknowledgment emphasizes that people tend to rely on known alternatives or familiar sources. Particularly, official information sources are more credible and authoritative. The authorization method proposes that people more thoughtlessly believe sites in the form of ratings, feedback, and testimonial suggested by both known and unknown individuals. The heuristic of steadiness indicates that people frequently determine credibility by testing to assess if the information is reliable throughout several different sources. The heuristic selfconfirmation shows that, if it suits their expectations or preceding views, people frequently interpret information as credible. The heuristic probability violation reveals that websites that are unsuccessful to fulfil the standards of individuals are considered less credible. Lastly, the convincing intent heuristic indicates that information detected as partisan is not considered as reliable.

\section{Evaluation of Online Sources}

The rapid development of technology provides a new format for getting information that people can access information online. Online sources as also known as internet sources refer to materials that you find online. It provides people with authentic and real communicating English (Sari, 2016). Since the easy access offered by the internet is promising, most people rely on it to get online information. However, not all online sources available are credible. Therefore, it is suggested to evaluate the online sources because the study conducted by Brandt (1996) showed that information available from varied online sources mostly do not stress resources based on the objectivity and subjectivity of information required by users. Similarly, December (1994) stressed that no matter how good a website is, it would not be useful if it remains filled with low-quality, inappropriate and misleading 
information. Furthermore, Kovacs et al. (1994) emphasized the need to analyze information on the internet does not necessarily corroborate what is found but to find out the background as well as the capability of its author.

In a learning context, the importance of online sources is to define the method in information searching as Wu and Tsai (2005) stated that the evaluative principles about precision and effectiveness of information owned by internet users determine their approaches to search information in internet based-learning. Also, MaKinster et al. (2002, p. 167) stated that the students who can assess the quality of search engine results can also identify the effectiveness of web pages.

The importance of online sources credibility evaluation is also emphasized when people seek health information and advice online. As outlined by Kitchens \& Harle (2014) and Zhang (2013) that it is necessary for people in evaluating sources concerning health matters since the information obtained will influence their healthrelated behavior as well as decisions. Besides, Diviani et al. (2015) emphasized that source evaluation is indeed essential that the insufficient ability in evaluating information will lead to people's vulnerability. To sum up, doing the evaluation is necessary as it can help internet users to find credibility as well as the effectiveness of information that they find online.

\section{Searchers' Perception toward Online Sources Credibility Evaluation}

The easy access available online is not equal to the process of selecting credible sources. Searchers sometimes find it difficult to select credible sources as there are varied procedures to follow. Besides, challenges like insufficient filtering system, source acknowledgment make searchers get confused in determining the quality of online sources. Therefore, this creates various perceptions toward online sources of credibility evaluation. In the English native context, Rieh et al. (1998) confirmed that information source is one of the crucial aspects in determining searchers' perception toward online information credibility. It is found through their study that searchers prefer to access information online by surfing the web that they have known as credible from their peers or schools. This action is considered as an appropriate way to guarantee the credibility of sources because those searchers were doubtful to apply another way to evaluate the quality of sources without external authority. Meanwhile, Lackaff \& Cheong (2008) depicted different perceptions of students in understanding and interpreting online sources through their study that source authority is not the main aspect used by students in evaluating online information. On the other hand, the students apply other aspects assisting them to search and evaluate online information such as heuristic-based on appearance and organization. Small and Ferreira (1994) examined middle school students toward their perception in searching sources using printed and multimedia sources revealed that students take more effort in searching sources on the internet compared to print sources. It also stated that students showed more positive perceptions toward print sources than multimedia sources.

Another study illustrated the perception of the credibility of online sources is done by Mehrabi et al. (2009) through their survey exploring factors affecting non-academic professional staff on their perception toward media credibility. The finding showed that participants felt that television provides more credible information compared to the internet, another result of this study also found that there are correlations among issue, media dependence, and media use regarding perception on internet and television credibility. In a similar vein but different finding, Flanagin and Metger (2000), discussing the comparison of credibility information between television and the internet reveals that participants in this study considered information on the internet is as credible as on television.

While in EFL context, Shahibi et al. (2013) examined Malaysian students' perception toward the credibility of information on the internet showed that in determining the credibility of online information, students are more focused on information sources then followed by other aspects such as web design and review of other internet searchers. The study conducted by Ayu (2020) on online materials used by university students showed that the credibility of English web-based sources of foreign-language information seeker was useful to help them learn English. Another result of this study also depicted that the participants of this study tend to trust English language sources if it is familiar with them. This factor is motivated as they found it difficult to evaluate the credibility of online. Similarly, Komlodi et al. (2011) illustrated that people in their study were suffering when conducting online sources credibility assessment in foreign language searching. This issue is supported by the fact that they are not familiar with particular culture as well as the organization of information within which a language is spoken. As the result, it creates negative perceptions among searchers.

\section{Searchers' Behavior toward Online Sources Credibility}

Some studies depicted that there are some differences between EFL searchers' and English native searchers' criteria in evaluating the credibility of online sources. This discrepancy could be caused by certain aspects and factors that they consider to do so. For example, in the English native context, Fogg et al. (2003) 
indicated that when evaluating the credibility of online sources, the students more rely on the visual design sites compared to their content. Fidel et al (1999) also highlight through one of their findings of high school student's behavior in assessing the credibility of online sources that high school students are more concerned with the graphic and design of a website. Hirsh (1999) outlines the different criteria taken by an adult and young people in judging the credibility of web-based information that adult people tend to depend on accurateness and trustworthiness while young people more prefer topics and preferences. Bateman's (1999) survey on information credibility found that $48 \%$ of respondents of this study judging credibility of information based on accuracy, consistency, understanding, and well-written. Additionally, Hilligoss and Rieh (2008) who conducted a study toward the way undergraduate students specify criteria in evaluating the credibility of online information found that students use varied ways in determining the credibility of sources depending on the context or kind of information that they got comparing to use five criteria offered by Hillgoss and Rieh covering truthfulness, believability, trustworthiness, objectivity, and reliability.

While in EFL context, the study of Liu and Huang (2005) in a cross-cultural study in the United States and China toward the behavior of undergraduate and graduate student in judging credibility reported that undergraduate students depend on authors' name, reputation, and website reputation for their credibility evaluation while graduate students more rely on quality and accuracy of the information that they found online. Catherine's (2018) study using survey toward 400 Indonesian respondents in assessing the credibility of online sources by using Flaginin and Metzger credibility model: believability, accuracy, trustworthiness, bias, and completeness showed that people more rely on trustworthiness and completeness in determining the credibility of online sources. Savolainen (2011) through his explorative study examines criteria applied in judging the quality and credibility of information on the internet toward Finnish respondents showed that in evaluating the information credibility, the participants employ reputation, expertise, and honesty of the author's message as the main criteria in the argument while assessing the quality information, they apply positive criteria like validity and negative criteria like dishonesty.

Concerning the differences in choosing criteria in evaluating online sources' credibility, Callister (2000) confirmed that this issue is caused by the breakdown of the standard convention in choosing credibility on the internet. Another anecdote led the discrepancy could be supported by people's cognitive knowledge. Lang (2000) stated that people with a lack of cognitive ability are reluctant to process all messages that they get. Besides, they only choose some noticeable aspects in encoding, storing, and retrieving information. Lastly, the factor that creates varied criteria in credibility evaluation is unnoticed elements provided by websites. Fogg (2003) states that since there are some elements in a website that cannot be detected by users, those elements are excluded in users' credibility evaluation.

\section{CONCLUSION}

Regarding with evaluation of online sources' credibility, people have different perspectives in selecting the criteria depend on the source and context of information that they obtain. The unwillingness of evaluating sources' credibility can be caused by varied factors, for example, numerous approaches in determining the quality of information that create confusion. For foreign language searchers, language proficiency is considered as the main aspect that makes them demotivate to judge the quality of the information in English. All in all, no matter what factors support the refusal of assessing the credibility of online sources, evaluation is indeed essential to be applied to avoid the use and spread of fake news, hoaxes and fabricated information.

\section{REFERENCES}

Alexander, J. E. \& Tate, M. A. (1999). Web Wisdom: How to Evaluate and Create Web Page Quality on the Web. Hillsdale, NJ: L. Erlbaum Associates Inc.

Ayu, M. (2020). Online learning: Leading e-learning at higher education. The Journal of English Literacy and Education, 7(1), $47-54$.

Bateman, J. (1999). Modeling the Importance of End-user Relevance Criteria. In Woods, L. (Ed.), Proceedings of the $62^{\text {nd }}$ Annual Meeting of the American Society for Information Science, Washington D.C., October 31- November 4, 1999 (pp. 396-406)/ Medfrod, NJ: Information Today, Inc.

Brandt, D. S. (1996). Evaluating Information on the Internet. Computers in Libraries, 16(5), 44-46.

Callister, T. A., Jr. (2000). Media literacy: On-ramp to the Literacy of the 21 st Century or Cul-de-sac on the Information Superhighway. Advances in Reading/Language Research, 7, 403-420.

Catherine, Y. (2018). 'Indeks kredibilitas Media Online: Studi Deskriptif Kredibilitas Media Online di Jakarta di Mata Generasi Millennial', Bachelor thesis, Universitas Multimedia Nusantara, Jakarta.

Diviani, N., Den, P., B., Giani, S., Van, W. (2015). Low health literacy and evaluation of online health information: A systematic review of the literature. J Med Internet Res, 17(5).

December, J. (1994) Challenges for web information providers. Computer-Mediated Communication. 1, 8-24. 
Fisher, J., Burstein, F., Lynch, K., Lazarenko, K. 2008. Usability + Usefulness= Trust: An exploratory Study of Australian Health Websites. Internet Research, 18(5), 477-498.

Fidel, R., Davies, R., K., Douglas, M., H., Holder, J., K., Hopkins, C., J., Kushner, E., K., Miyagishima, B., K., \& Toney, C., D. (1999). A visit to the information mall: Web Searching Behavior of High School Students. Journal of the American Society for Information Science, 50(1), 24-37.

Flanagin, A. J. \& Metzger, M. J. (2008). Digital Media and Youth: Unparalleled Opportunity and Unprecedented Responsibility. Cambridge, MA: MIT Press.

Flanagin, A.J., \& Metzger, M.J. (2000). Perceptions of Internet Information Credibility. Journal of Mass Communication Quarterly, 77(3), 515-540.

Fogg, B. J. (2003). Prominence-Interpretation Theory: Explaining How People Assess Credibility Online. In Proceedings of the Extended Abstracts on Human Factors in Computing Systems, Fort Lauderdale, Florida, USA (pp. 722-723). New York, NY: ACM.

Forzani, E. (2018). How Can Students Evaluate Online Science Information? Contributions of Prior Knowledge, Socio Economic Status and Offline Reading Ability. Reading Research Quarterly, 53(4), 385-390.

Hilligoss, B., \& Rieh, S. S. Y. (2008). Developing a Unifying Framework of Credibility Assessment: Construct, Heuristics, and Interaction in Context. Information Processing \& Management, 44(4), 1467-1484.

Judd, V. C., Farrow, L. I., \& Tims, B. J. (2006). Evaluating Public Web Site information: A Process and an Instrument. Reference Service Review, 34(1), 12-32.

Kitchens, B., Harle, C., \& Li, S. (2014). Quality of Health-Related Online Search Results. Decision Support Systems, 57, 454462.

Komlodi, A., Jozsa, E., Koles, M., Hercegi, K. (2011). Search Quality Differences in Native and Foreign Language Searching. In proceeding of the Human-computer Information.

Lackaff, D \& Cheong, P., H. (2008). Communicating Authority Online: Perceptions and Interpretations of Internet Credibility among College Students. The Open Communication Journal, 2, 143-155.

Oktaviani, L. \& Desiarti, E. (2017). A Lecturer's and Students' Perspective toward Ethnic Snake Game in Speaking Class at Universitas Muhammadiyah Malang. TEKNOSASTIK: Journal Bahasa dan Sastra. 15(2), 53-59. DOI: https://doi.org/10.33365/ts.v15i2.98

Oktaviani, L. \& Mandasari, B. (2020). Powtoon: A Digital Medium to Optimize Students' Cultural Presentation in ELT Classroom. Teknosastik: Jurnal Bahasa dan Sastra, 18(1), 33-41. DOI: https://doi.org/10.33365/ts.v18i1.526.

Rieh, S., Y. (2014) Credibility Assessment of Online Information in Context. Journal of Information Science Theory and Practice, 2(3), 06-17.

Rieh, S. Y. (2010) Credibility and cognitive authority of information. Encyclopedia of Library and Information Sciences, 1(1), 1337-1344.

Sari, F. M. (2016). Internet-Based Materials in Enhancing College Students' Writing Skill Viewed from Their Creativity. Teknosastik: Jurnal Bahasa dan Sastra, 14(1), 41-45.

Sari, F. M. (2020). Exploring English Learners' Engagement and Their Roles in the Online Language Course. Journal of English Language Teaching and Linguistics, 5(3), 349-361.

Savolainen, R. (2011). Judging the Quality and Credibility of Information in Internet Discussion Forums. Journal of the American Society for Information Science and Technology, 62, 1-25.

Serafni, F. (2012). Reading Multimodal Texts in the 21st Century. Research in the Schools, 19(1), 26-32.

Shahibi, S., S., Mazlan, M., A., Noor, M., H., \& Hanafiah, M., S., M. (2013). Perception toward the Credibility of Information in Internet among Young Malay Generation. International Journal of Education and Research, 1(7), 1-8.

Young, A.L. Komlodi, A., Rozsa, \& G. Chu, P. (2016). Evaluating the Credibility of English Web Sources as a Foreign Language Searcher. Proceeding of the Association for Information Science and Technology, 53(1), 1-9.

Zhang, Y. (2014). Searching for Specific Health-Related Information in MedlinePlus: Behavioral patterns and user experience. Journal of the Association for Information Science and Technology, 65(1), 53-68.

\section{BIOGRAPHY OF AUTHOR}

Fatimah Tuzahra is an English education student of the Magister program of Sriwijaya University. Her research interest is on critical literacy, digital literacy, and technology in teaching. 